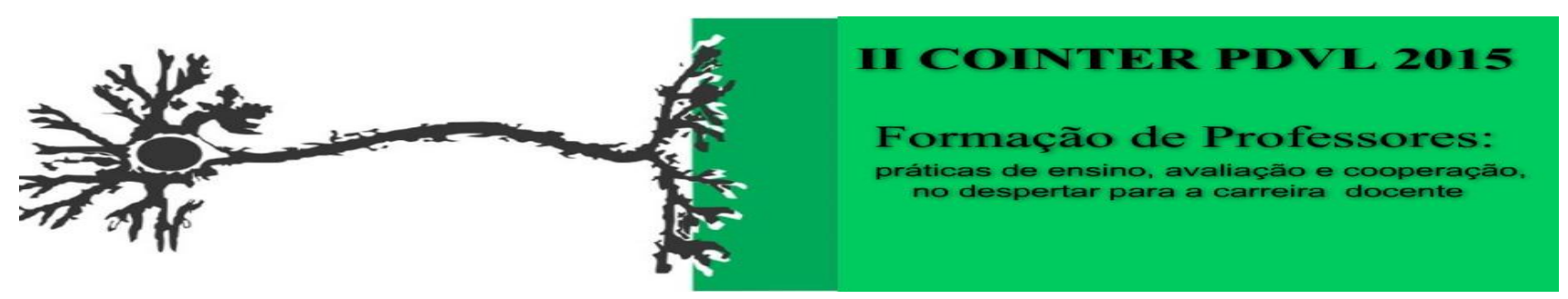

\title{
O IMPACTO DA FEIRA DE CIÊNCIAS NO PROCESSO DE APRENDIZAGEM: UM PONTO DE VISTA DOS DISCENTES.
}

\author{
Apresentação: Relato de Experiência \\ Andson Kelvin S. Rocha ${ }^{1}$; Julia Taisy Bezerra do Vale ${ }^{2}$ Jan Pierre Modesto Alves ${ }^{3}$; Indira \\ Alves dos Santos ${ }^{4}$; Deivd Porto de Andrade ${ }^{5}$
}

\section{Introdução}

As barreiras encontradas pelos discentes na sala de aula, geralmente podem estar relacionadas a fatores metodológicos, como por exemplo, a falta de relação dos conteúdos com o contexto em que em que os alunos estão inseridos. Isso implica em algumas dificuldades de aprendizagem. A feira de ciências proporciona uma aproximação uma experiência, no qual os próprios contextualizam e constroem o conhecimento cientifico. O objetivo é avaliar a perspectiva dos alunos em relação a feira de ciência, e criar possibilidades para que os alunos tenham a representatividade diante das suas produções cientificas. Segundo Farias (2006) as feiras de ciências contribuem para a socialização e troca de experiências no processo de ensino e aprendizagem.

\section{Relato de Experiência}

Este relato de experiência apresenta o acontecimento de uma feira de ciência e tecnologia ocorrida durante a Semana Nacional de Ciência e Tecnologia de $2015 \mathrm{com}$ alunos de $2^{\circ}$ e $3^{\circ}$ anos do ensino médio da Escola de Referência em Ensino Médio Dr. Pacífico Rodrigues da Luz, no município de Petrolina-PE. A feira foi desenvolvida com a ajuda de 198 alunos, a professora de física e também supervisora do Programa Institucional de Bolsa de Iniciação à Docência-PIBID e 4 alunos bolsistas do PIBID, sendo 2 deles autores desde relato.

As etapas para a elaboração deste projeto foram planejadas entre os professores da escola e os alunos bolsistas. Porém, as atividades experimentais foram elaboradas pelos próprios alunos sob a orientação dos bolsista. Estas atividades desenvolvidas foram de grande importância para o processo de aprendizagem dos alunos, pois os mesmos puderam planejar, aprofundar os

\footnotetext{
${ }^{1}$ Estudante de Licenciatura em Física, IF Sertão Pernambucano, andsonkelvin@hotmail.com

${ }^{2}$ Estudante de Licenciatura em Física, IF Sertão Pernambucano, julia_taisy@hotmail.com

${ }^{3}$ Estudante de Licenciatura em Física, IF Sertão Pernambucano, pierremodesto@hotmail.com

${ }^{4}$ Estudante de Licenciatura em Física, IF Sertão Pernambucano, indira.alves2012@hotmail.com

${ }^{5}$ Professor de licenciatura em física, IF Sertão Pernambucano, deivd.porto@hotmail.com
} 
conhecimentos científicos, amadurecer a forma com que a experimentação é trabalhada na escola e vivenciar experiências que fogem das aulas tradicionais, resumidas a quadro branco e pincel.

De forma geral, os alunos que participaram diretamente da elaboração dos projetos foram multiplicadores dos conhecimentos adquiridos nas pesquisas e experiências desenvolvidas, motivando outras turmas a participarem como espectadores destas atividades e de futuras feiras de ciências.

\section{Considerações}

Com esse trabalho pode-se observar o desenvolvimento, por parte dos alunos, da criativa. Além disso, pudemos perceber um aprendizado decorrente da construção de experimentos aliado a uma fundamentação teórica que os mesmos tiveram que buscar para explicar os fenômenos físicos e químicos presentes nos mesmos

As observações e as produções cientificas apresentadas pelos alunos na feira de ciências na escola estadual EREM Dr. Pacifico Rodrigues da Luz mostraram que os discentes estabeleceram uma interação interdisciplinar no desenvolvimento do projeto estabelecendo uma relação entre a teoria e a pratica, de forma que as atividades realizadas estimulam a investigação e a socialização entre o grupo.

\section{Referências}

MOREIRA, Marcos Antônio. Teorias de Aprendizagem. $2^{\text {a }}$ Edição. São Paulo: EPU, 2011. ARAÚJO, M.S.T; ABIB, M.L.V.S Atividades Experimentais no Ensino de Física: Diferentes Enfoques, Diferentes Finalidades. Revista Brasileira de Ensino de Física. v.25, №2, Jun-2003 GOMES, L.C. Uma atividade pratica motivadora para o aprendizado dos conceitos de reflexão e refração da luz. Revista Ciência e Ensino, vol. 2, N¹,Dez-2007

FARIAS, L.N. Feira de ciências como oportunidade de (re)construção do conhecimento pela pesquisa. 2006.89. F. Dissertação (Mestrado em Educação em Ciências e Matemáticas) - Núcleo Pedagógico de apoio ao desenvolvimento cientifico, Universidade federal do Pará, Belém, 2006.

Secretária de Educação Básica. Programa Nacional de Apoio às Feiras de Ciências. Fenaceli Brasília: MEC/ SEB, 2006 B. 